\title{
Estudos da cultura empreendedora no campo da comunicação: macroproposições, narrativas, inspiração ${ }^{1}$
}

\author{
Vander Casaqui' \\ I - ESPM
}

São Paulo (SP), Brasil

Resumo: Este trabalho tem como objetivo situar o estudo da cultura empreendedora no campo da comunicação, a partir de suas problemáticas. Para tanto, tratamos da presença dos discursos relativos ao empreendedorismo no cenário midiático, assim como abordamos os processos comunicacionais complexos que envolvem a atividade empreendedora, por meio dos discursos de seus agentes e institucionalidades. A noção de inspiração é apresentada como central para as formas comunicacionais que organizam a ideologia empreendedora em sua publicização, em chave motivacional e positiva.

Palavras-chave: comunicação e consumo; cultura empreendedora; discurso social; inspiração.

Abstract: Entrepreneurial culture studies in the field of communication: macropropositions, narratives, inspiration - This paper aims to situate the study of entrepreneurial culture in the field of communication, based on its problems. Therefore, we deal with the presence of the discourses related to entrepreneurship in the media scenario, as well as we approach the complex communication processes that involves the entrepreneurial activity, through the discourses of its agents and institutions. The notion of inspiration is presented as a central point to the communicational forms that organize the entrepreneurial ideology in its publicity, in a motivational and positive manner.

Keywords: communication and consumption; entrepreneurial culture; social discourse; inspiration.

1 Artigo apresentado no Grupo de Trabalho Comunicação e Consumo: Cultura Empreendedora e Espaço Biográfico, do $6^{\circ}$ Encontro de GTs de Pós-Graduação - Comunicon, realizado nos dias 14 e 15 de outubro de 2016, tendo permanecido inédito na sua versão escrita. 


\section{Introdução}

Neste trabalho, procuramos delimitar as problemáticas que envolvem o estudo do empreendedorismo como cultura e como fenômeno comunicacional, identificando o lugar da "inspiração" nos processos discutidos. De forma distinta de outros campos que discutem o empreendedorismo, como a administração e a economia em sua perspectiva pragmática; ou mesmo a sociologia que aborda as questões econômicas e/ou do mundo do trabalho, o campo da comunicação tem como peculiaridade a compreensão desse tema a partir de sua materialidade discursiva, dos dizeres e saberes que se difundem e constituem a teia social, na qual nos situamos. De acordo com Clifford Geertz (2008), o conceito de cultura é essencialmente semiótico, uma vez que o homem é um ser amarrado a teias de sentido, a tramas comunicacionais que constituem a sociedade e atribuem significados às práticas, aos papéis sociais, aos devires, aos sonhos e desejos dos indivíduos que nela habitam. É nesse espectro que identificamos o empreendedorismo como discurso social (ANGENOT, 2010), em seus processos comunicacionais e na forma como mobiliza a noção de inspiração para convencer, fazer crer, seduzir, engajar os indivíduos para os quais esse discurso social é direcionado.

A proposta teórico-metodológica de Angenot aponta para a leitura dos discursos em um recorte temporal e em seu espraiamento; o discurso social, como expressão do espírito de nosso tempo, é identificado por uma espécie de onipresença, por ser percebido em múltiplos lugares, em diversas esferas de atuação humana, do mundo do trabalho à vida cotidiana. É o caso dos discursos que compõem a cultura empreendedora, como procuramos defender nessa pesquisa. Como visada panorâmica, este estudo busca identificar manifestações dessa cultura a partir da noção de inspiração. Elegemos essa noção como chave para compreensão do empreendedorismo como objeto da comunicação, uma vez que consideramos o uso da inspiração nesse cenário como a construção de uma interação ideal, utópica, que envolve a relação imaginada entre produtores e consumidores dos discursos, em suposto alinhamento e em chave positiva. Em síntese: no projeto de sociedade empreendedora, os agentes dessa cena elegem a inspiração como forma de propagar a "boa nova", o ideário em sintonia com a sociedade neoliberal discutido por Dardot e Laval (2016). Uma sociedade idealizada como ambiente de inspirações mútuas, de harmonia para a transformação do mundo em um lugar planejado, conduzido e habitado por empreendedores. Eis a expressão da utopia pregada pelo guru do marketing Peter Drucker (2011).

Nesse cenário composto por uma profusão de discursos, observamos, com especial interesse, a constituição de um mercado de ideias, com diversos agentes disputando a legitimidade da fala para diagnosticar nossa era e prescrever comportamentos para quem deseja se alinhar a esse admirável mundo novo. Vejamos um exemplo dessa tomada de voz, que utiliza a noção de inspiração como central para sua argumentação e sua justificação: 
Estamos vivendo em um emaranhado de constante informação e mesmo assim nos deparamos com uma crise de novas ideias. O mercado da criatividade, da tecnologia e da inovação procura diariamente por novas fontes de inspiração que insistem em se repetir - é a tal crise da inspiração que nos cercou. Parece difícil encontrar algo genuíno ou interessante, e de fato é. Como se tudo já tivesse sido exposto e muita coisa já perdeu a graça. Pra encontrar a verdadeira matéria-prima da inspiração, aquela que nos energiza e emociona, precisamos ir fundo, ir longe, descobrir novos ares, novas pessoas e principalmente novos discursos. Precisamos de uma expedição. O LiveTalks 2016 te convida para nossa Expedição Para Inspiração. ${ }^{2}$

Com o título de "Uma expedição para inspiração", o evento LiveTalks, cujo slogan é "inspire a mudança", convida a todos para uma jornada em busca da "matéria-prima da inspiração", para superar a "crise de novas ideias", para que seus participantes saibam como encontrar "algo genuíno ou interessante" num mundo que estaria saturado de repetições, de excesso de informação. O anúncio da nova era é o convite a "ir fundo, ir longe, descobrir novos ares, novas pessoas e principalmente novos discursos". O LiveTalks é definido como um espaço de "inspiração e provocação" - um "encontro único de pessoas transformadoras", capazes de tomar parte em "grandes conversas" e assim promover a "mudança", a "transformação":

LiveTalks é uma forma de compartilhamento e abastecimento de ideias, tendências e novidades, através de um encontro único entre pessoas transformadoras. Quando juntamos quem já fez com quem quer fazer a mudança, grandes conversas se cruzam e surge um potencial verdadeiro de transformação. ${ }^{3}$

A ideia da expedição para inspiração utilizada como mote para a comunicação do LiveTalks sugere uma viagem, que, pelos termos em que é descrita, está baseada na perspectiva da jornada interior, no despertar do empreendedor de si mesmo (FOUCAULT, 2008), na busca pelo eu autêntico (FREIRE FILHO, 2010; TAYLOR, 2011). Quando se trata de "ideias, tendências e novidades", percebemos mais claramente o universo em que essa interação se realiza: trata-se do mercado de palestras e eventos motivacionais, que temos denominado autoajuda empreendedora. Nesse universo o novo espírito do capitalismo se faz presente: o mundo conexionista discutido por Boltanski e Chiapello (2009) se faz perceber em toda sua exuberância e sua mística, em sua capacidade de "energizar e emocionar". O mundo do networking, das startups, dos espaços de coworking, do trabalho colaborativo, da criatividade humana aplicada à concepção de novos negócios, novos produtos, novas formas de produzir e se relacionar sob a égide do capitalismo contemporâneo. Como reitera o discurso da Endeavor, uma das principais organizações de incentivo ao empreendedorismo no mundo, cuja representação no Brasil

2 Fonte: <http://www.livetalks.com.br/>. Acesso em: 18 set. 2016. Grifos do original.

3 Fonte: <http://www.livetalks.com.br/>. Acesso em: 18 set. 2016. 
traz a seguinte síntese sobre a importância do networking para os negócios e para a vida do empreendedor como um todo:

Como empreendedor, o Networking pode ser fundamental para o crescimento do seu negócio. Mas não apenas isso, pode ser um processo de construção de amizades motivada por interesses mútuos. Cultivando conexões genuínas, sua rede de contatos pode ser ampliada inclusive de forma espontânea, conforme você e seu negócio causam boas impressões e são referenciados. Com um pouco de prática, seu capital social se torna cada vez mais valioso, expandindo sua capacidade de formar relacionamentos sólidos, pessoais e profissionais. ${ }^{4}$

Essa cena discursiva está baseada nas macroproposições (VAN DIJK, 1978) desse momento histórico, em que o empreendedorismo ultrapassa a atividade econômica para se estabelecer como diretriz para a transformação de todas as esferas da vida. Safatle (2015) parte da noção do "ideal empresarial de si" como paradigma desse tempo. Ehrenberg (2010) trata do empreendedor como modelo de cultura, assim como Boltanski e Chiapello (2009) localizam o cenário da emergência do empreendedor como modelo no movimento cíclico de renovação retórica do capitalismo, cujo objetivo é manter a atratividade do sistema e sua capacidade de promover o engajamento das novas gerações. Em sua pesquisa de doutorado, Júlia Salgado (2016) identifica, nas representações e discursos veiculados no jornal Folha de São Paulo, o processo histórico que alça o espírito empreendedor ao patamar de designação de sujeito ideal, tanto para o mundo do trabalho como para a vida como um todo, inclusive em seu momento de morte, nos obituários que narrativizam sua trajetória e buscam apontar seu legado para a sociedade e para as futuras gerações. Nesse sentido, o perfil heroico, apolítico, acima do bem e do mal que é associado ao empreendedor se mantém forte, potente, em tempos de crise e transformação do capitalismo. Como balanço em relação a esses estudos, tão úteis quanto relevantes para estabelecermos as relações entre comunicação e empreendedorismo, afirmamos a importância da abordagem comunicacional para a compreensão do "espírito" do tempo, em que os processos de mediação e midiatização amplificam as vozes dos agentes associados ao campo do empreendedorismo.

\section{A inspiração: vertentes e sua relação com a cultura empreendedora}

Este trabalho é desenvolvido no momento em que acontecem os Jogos Paralímpicos de 2016, realizados no Rio de Janeiro. Após as demonstrações dos atletas de alta performance e seus corpos perfeitos, presentes nos Jogos Olímpicos, as Paralimpíadas apresentam competidores demasiadamente humanos. Indivíduos com deficiências corporais, cognitivas, que sofreram acidentes, que trazem doenças congênitas - atletas que,

4 "Entenda a importância do Networking para sua empresa". Matéria disponível em: https://endeavor.org.br/ entenda-importancia-networking-empresa/. Acesso em: 1/5/2017. 
de alguma forma, não são caracterizados como modelos ideais de uma cultura fundada no consumo e no desempenho, a cultura midiática de nosso tempo. No entanto, há algo de performático na disputa paralímpica, que atrai o olhar, provoca empatia e nos desafia a "superar nossos obstáculos" - uma vez que, para serem competitivos, para representarem seus países nesse evento, para serem reconhecidos como vencedores, esses indivíduos superaram as limitações corporais, os estigmas, as dificuldades de diversas naturezas. Não à toa, um dos valores específicos dos Jogos Paralímpicos é a inspiração - no material de divulgação da competição sediada no Rio de Janeiro em 2016, a imagem associada a esse valor paralímpico é a do atleta Daniel Dias ${ }^{5}$, o maior vencedor da natação masculina paralímpica de todos os tempos, o maior medalhista de nossa história na competição. A inspiração, nesse cenário, é baseada no estímulo à inclusão dos deficientes, a um contrato social mais amplo que o da igualdade somente para os corpos "normais", ao dar visibilidade aos indivíduos geralmente marginalizados em nossa sociedade. Esse exemplo se refere a um significado mais amplo da inspiração, que escapa ao recorte delimitado para este estudo - uma vez que compreendemos que a inspiração, em nossa pesquisa, está a serviço da difusão do "ideal empresarial de si" (SAFATLE, 2015).

Como discutimos em trabalho anterior (CASAQUI, 2015), há uma historicidade da noção de inspiração que permite perceber onde se situa o nosso objeto. Thrash e Elliot (2003) apontam três vertentes para compreensão da inspiração: a primeira, relativa a fontes transcendentes ou sobrenaturais, é originária da religião e das artes. No caso da inspiração religiosa, há um processo de revelação (transmissão dos preceitos religiosos vindos de Deus) e inspiração (transposição da revelação divina para a língua humana, a fim de que a palavra de Deus chegue aos homens). No caso das artes, as mitológicas Musas são fonte de inspiração para os artistas, como os escritores, poetas, pintores, considerando-se essa produção como uma elevação do espírito humano. A segunda vertente são as fontes intrapsíquicas da inspiração: com o advento da disciplina psicológica, bem como a emergência da sociedade da produção derivada da segunda Revolução Industrial, a inspiração é incorporada ao processo produtivo de ideias, da inovação, da criatividade cooptada pelo sistema capitalista.

A terceira vertente, que nos interessa particularmente, é a que se baseia na inspiração por fatores ambientais: a influência do ambiente para inspirar é algo que se pode perceber na arquitetura para o trabalho no espectro da chamada "economia criativa", nas atividades de empreendedorismo em espaços de coworking, em que a estética, as dinâmicas como o design thinking, entre outros estímulos, têm como papel inspirar a inovação, a criatividade, o processo de conceber negócios, novos produtos, transformar o mercado e simultaneamente a si mesmo, no sentido do "empreendedor de si" discutido por Foucault (2008). As narrativas inspiracionais de agentes relacionados com o empreendedorismo

5 Fonte: https://www.rio2016.com/educacao/midiateca/agentes-jovens/cartazes-valores-olimpicos-eparalimpicos?page=1. Acesso em: 10 set. 2016. 
também se encaixam nessa terceira vertente: o empreendedor, como modelo de cultura, é tratado como fonte de inspiração de um projeto de sociedade, o projeto da sociedade empreendedora imaginado por Drucker (2011), um dos autores referenciais desse modelo. Dessa forma, a difusão de histórias de vida, tidas como jornadas empreendedoras de sucesso, implicam um modelo comunicacional bem definido, cujo objetivo é a reprodução generalizada da trajetória do empreendedor ideal, estimulada por cadeias de produção - circulação - consumo de narrativas. A já citada Endeavor, na apresentação de sua missão, traz mais elementos para observarmos como opera a comunicação no projeto da sociedade empreendedora, do qual a instituição é um dos principais ativistas no Brasil e em outras partes do mundo:

A Endeavor é a organização líder no apoio a empreendedores de alto impacto ao redor do mundo. Presente em mais de 20 países, e com 8 escritórios em diversas regiões do Brasil. Acreditamos que a força do exemplo é o caminho para multiplicar empreendedores que transformam o Brasil e por isso trazemos aprendizados práticos e histórias de superação de grandes nomes do empreendedorismo para que se disseminem e ajudem empreendedores a transformarem seus sonhos grandes e negócios de alto impacto. ${ }^{6}$

No discurso da Endeavor, destacamos a expressão "força do exemplo", que traduz o objetivo da instituição em termos comunicacionais. Ou seja, a divulgação da imagem de empreendedores de sucesso é parte significativa de sua estratégia de disseminar a cultura empreendedora no país pela via da inspiração. Essa inspiração é derivada da imagem construída do empreendedor - tido como um semideus imaculado, positivo, incontestável, imune às tentações dos negócios escusos, mesmo em tempos em que empresários são expostos na mídia como parte de redes de corrupção historicamente arraigadas na política brasileira. Entre os atributos associados ao empreendedor pela Endeavor, está "fonte de inspiração", assim como "ser exemplo" - ambos se referem à perspectiva de estudos que aqui discutimos, a inspiração no contexto da cultura empreendedora. Dardot e Laval (2016) defendem que a nova razão do mundo é baseada nas lógicas do neoliberalismo, das quais o empreendedor é a expressão mais bem acabada; Safatle (2015) vai propor a noção de circuito dos afetos, para tratar do capitalismo neoliberal. Ambos os aspectos, racionalização e passionalidade, aliam-se na constituição da formação discursiva do empreendedorismo.

\section{A narrativa de Bel Pesce em questão e a irrupção da negatividade}

Um dos acontecimentos mais curiosos da cena empreendedora brasileira, para compreender a cultura da inspiração em seus aspectos míticos, é o caso recente que envolve a biografia de Bel Pesce, ou melhor, as narrativas que constituem a sua jornada

6 Disponível em: < https://endeavor.org.br/entenda-importancia-networking-empresa/>. Acesso em: 17 set. 2016. 
empreendedora, nas palavras da própria personagem. Autora do best seller do que chamamos de autoajuda empreendedora, o livro A Menina do Vale (PESCE, 2015), Bel Pesce promoveu sua trajetória narrativizada como uma forma de inspirar novos empreendedores, como fica evidente no prefácio assinado por Flávio Augusto (SILVA, 2015), mais um agente proeminente dessa cena, autor de outro sucesso de vendas, o livro Geração de Valor.

Considerada desde o sucesso do seu primeiro livro como líder inspiradora de uma geração, Bel Pesce investiu na tal jornada empreendedora e ficou progressivamente conhecida, especialmente nos espaços de difusão do empreendedorismo no Brasil. Foi escolhida como uma das líderes da campanha global da marca de uísque Chivas Regall, baseada num concurso que premia as melhores ideias empreendedoras, intitulado The Venture, que procura aplicar a equação sustentada pela marca como espírito de um novo capitalismo: lucro + propósito = sucesso. Lançou diversos livros na mesma perspectiva da inspiração do outro, que parte da narrativização da própria experiência. Montou uma agência e se envolveu em diversos projetos de empreendedorismo, o que a manteve na cena midiática como uma empreendedora de sucesso, de acordo com o paradigma da visibilidade contemporânea - em que a mise-en-scène, os modos de parecer alimentam a leitura do ser vencedor.

Um acontecimento, no entanto, vai demonstrar o quão complexo é o circuito comunicacional em que se dá a emergência e, muitas vezes, a derrocada dos chamados empreendedores de palco. Envolvida com um projeto tido como oportunista por parte de seus seguidores nas redes sociais, Bel Pesce se junta ao vencedor da edição de 2016 do reality show televisivo Masterchef Brasil - Leonardo Young, o Leo - e com Zé Soares - que encabeça o blog "Do Pão ao Caviar" - para anunciar o lançamento da Hamburgueria Zebeleo, no badalado bairro paulistano da Vila Madalena, poucos dias após a final do Masterchef que deu a vitória a Leo. O que parecia o plano perfeito, no entanto, acabou tendo sentido inverso: ao inserirem o projeto de negócios em uma plataforma de crowdfunding, ou seja, ao proporem uma "vaquinha eletrônica" para captar R \$ 200 mil reais para investir no negócio próprio, os seus responsáveis passaram a ser atacados nas redes, questionados em sua ética, em sua "esperteza" e, em última instância, no caráter de seu sucesso. Especialmente esse último ponto se refere à narrativa de vida de Bel Pesce: os "fatos" de sua vida passaram a ser questionados, como a quantidade de cursos realizados, a participação ou não em fundações de empresas no Vale do Silício, entre outros aspectos - levando-a a enfrentar os seus juízes virtuais com a reafirmação de sua narrativa de sucesso, apresentando imagens de diplomas e certificados, fotografias, entre outros comprovantes digitalizados e comentados. Sucedeu-se uma desconstrução midiática das mais ferozes, com momentos hilários, como a sucessão de "erramos" de diversas matérias divulgadas pelo site UOL em 2012, revisadas em 2016, que exemplificamos abaixo: 
CORREÇÃO: A versão original desta reportagem continha informações erradas. A empreendedora brasileira Bel Pesce não concebeu o projeto, não foi a única nem a principal fundadora da empresa dos EUA Lemon (aplicativo de finanças pessoais), como dava a entender o texto. Ela foi membro da equipe fundadora, à qual se juntou pouco depois de formada a equipe original. O texto foi corrigido. Leia também reportagem sobre a polêmica das qualificações da empreendedora.?

Sem que precisemos nos deter em mais detalhes sobre o caso, identificamos que o ideal da sociedade positiva problematizado por Han (2013), ou seja, do projeto de sociedade que busca apagar a negatividade, em favor da aceleração da comunicação entre iguais (que Han vai chamar de "o inferno do igual") - o projeto da sociedade empreendedora -, pouco resiste aos embates dos discursos como observamos nas redes sociais, em que a "inspiração" convive com o ódio, com o preconceito, com a violência, com um complexo circuito dos afetos. Baseada numa chave positiva, motivacional, a história de Bel Pesce pareceu não resistir a um olhar mais atento, à crítica, à negatividade, que precisaria ser banida para o sucesso duradouro da mitificação de sua trajetória. Seu universo mítico se alinha à perspectiva da noção de inspiration economy - defendida pelo Journal of Inspiration Economy (GALOUJ, 2014), lançado pela University of Bahrain -, em que os agentes econômicos e da sociedade como um todo, mais do que competirem, estabelecem relações de "inspiração mútua".

Em contraponto a esse mundo ideal, a percepção de que as ações em torno da Hamburgueria Zebeleo feriram os princípios da comunidade de empreendedores que "inspiram uns aos outros" foi uma espécie de acontecimento (PRADO, 2016), que promoveu um realinhamento das narrativas posteriores de seus responsáveis. Leo parece ter perdido grande parte do capital simbólico que adquiriu pela vitória no programa televisivo, em questão de dias. Bel Pesce passa a ser acusada de não ser "autêntica" (TAYLOR, 2011), de não ser uma legítima empreendedora de sucesso. Seu ethos discursivo se torna responsivo, e a inspiração dá lugar à postura defensiva, em ciclos de ataques e defesas em torno de sua própria narrativa. Entre outras coisas, a ridicularização de Bel Pesce através de memes é uma derivação do acontecimento que irrompe em tensionamento à sua trajetória particular. Um dos mais corrosivos desses memes a circularem na internet é uma montagem a partir de fotografia com a equipe fundadora da megacorporação Microsoft, datada de 1978, incluindo o mítico Bill Gates e seus sócios. Bel Pesce aparece em meio à equipe, na imagem que tem como título a pergunta: "O que há de errado com a imagem? (alguns dirão nada)". Obviamente, trata-se de uma sátira com a menina de aproximadamente 28 anos de idade em 2016, ou seja, com dez anos de vida quando foi tirada a fotografia em questão. Uma ironia que faz alusão direta às histórias, colocadas

7 Fonte: < http://economia.uol.com.br/noticias/redacao/2012/06/01/conheca-a-historia-de-bel-pesce-a-meninaque-conquistou-o-vale-do-silicio.htm>. Acesso em: 1/5/2017. 
em xeque, da participação de Bel na fundação de empreendimentos na Meca da cultura empreendedora contemporânea, o Vale do Silício, nos EUA.

As consequências desse acontecimento para sua carreira ainda não podem ser bem compreendidas, dada a impossibilidade de afastamento temporal para mapear e analisar os seus desdobramentos. No entanto, o que pode ser visto representa o contraponto da sociedade positiva, ou seja, a irrupção de uma perspectiva dialógica da vida cotidiana, no sentido dos embates ideológicos em torno dos signos, como trata Bakhtin (1997). O que implica, entre outras coisas, o reconhecimento dos aspectos políticos que envolvem os discursos, algo que é dissimulado no contexto da cena midiática do empreendedorismo, o que discutimos a seguir.

\section{Para concluir: o papel da inspiração nas dissimulações do político}

Vivemos em um tempo em que os discursos sobre empreendedorismo, economia criativa, nova economia, "capitalismo artista", entre outras denominações, emergem como sinais de uma espécie de nova era, de um capitalismo de "propósitos", que aliaria a busca do lucro com a felicidade, com a realização dos sonhos, com a ética da "gente de bem", com um ambiente de criatividade generalizada e supostamente democrática. Um ambiente idealizado em que todos inspiram e são inspirados; em que a economia, as práticas sociais, a comunicação, tudo se alisa, se dinamiza e se acelera, em fluxos promovidos pelos contatos entre iguais, entre pessoas em plena sintonia e que partilham os mesmos objetivos, os mesmos modos de ser e de perceber o mundo.

Os discursos que publicizam a imagem do empreendedor e seu ideário, de maneira recorrente, reforçam o seu suposto caráter "apolítico". Essa visão antipolítica é contraposta por Mouffe (2015), que aponta ser essa postura uma tentativa de criar um mundo "'além da esquerda e da direita', 'além da hegemonia', 'além da soberania' e 'além do antagonismo'”'(ibidem, p.2). Ainda de acordo com Mouffe, os conflitos políticos são dissimulados, lançados para a esfera moral. Dessa maneira, os embates entre ideologias passam a ser tratados como a dicotomia entre o "certo e o errado", entre o "nós e o eles" (ibidem, p.5).

A inspiração tem um papel chave na construção dos discursos articulados à cultura empreendedora; o papel de esvaziar o caráter político do projeto da sociedade empreendedora, ao passo em que mobiliza o circuito dos afetos positivos, da chave motivacional para falar aos "corações e almas" (SAFATLE, 2016, citando entrevista dada por Margareth Thatcher), em favor da manutenção das lógicas do neoliberalismo vigente. Colocado como paradigma moral, como modelo a ser seguido, como exemplo de trajetória a ser mimetizado, replicado, copiado, o empreendedor corresponde à tentativa de apagar a ideologia que é inerente ao ser social. Nesse caso, a ideologia é ressignificada como valor supremo, como macroproposição: a meritocracia é alçada ao nível da justiça universal, descolada de sua origem, ou seja, da sociedade neoliberal (DARDOT; LAVAL, 2016), dos interesses particulares em jogo e de suas mercado-lógicas. 
Seres com propósito, os empreendedores se apresentam como os líderes legítimos para conduzir o mundo a um futuro melhor. Seres com espírito empreendedor, que difundem a própria história de vida como narrativa de vida exemplar, para inspirar o outro a seguir sua jornada. Como bem define Bel Pesce em entrevista, ao ser questionada se "qualquer pessoa pode empreender":

Para ser empreendedor, você não precisa abrir uma empresa. Por exemplo, você pode empreender dentro de grandes companhias, criando um novo departamento ou fomentando novas ideias. Você pode empreender na faculdade, começando algum grupo de discussão sobre algo em que tenha interesse. Empreender está muito relacionado a ter iniciativa para começar algo em que você acredita. E, por esse ângulo, todos podem ter um espírito empreendedor. ${ }^{8}$

Afastando-se da ambição explícita do capitalista "selvagem", o empreendedor com propósito, fundado em suas crenças, renova a retórica do capitalismo e oferece uma aura de autenticidade ao sistema, tornando-o capaz de engajar novos quadros, à imagem e semelhança do homem que corresponde ao mundo conexionista descrito por Boltanski e Chiapello (2009). Um mundo baseado no networking, na produtividade das relações, na profusão do pensamento único - a monocultura empreendedora, que ambiciona se universalizar, tal qual se universalizou o ethos burguês, em seu triunfo derivado da consolidação da Revolução Industrial na segunda metade do século XIX. Esse pensamento único, no entanto, parece não resistir aos "curtos-circuitos" dos afetos correspondentes ao nosso tempo. A "Menina do Vale" que o diga.

Vander Casaqui é docente do Programa de Pós-Graduação em Comunicação e Práticas do Consumo da ESPM e doutor em Ciências da Comunicação pela Universidade de São Paulo (2005), com Pós-Doutorado pela Universidade Nova de Lisboa (2013).

vcasaqui@yahoo.com.br

\section{Referências}

ANGENOT, M. El discurso social: los limites históricos de lo pensable y lo decible. Buenos Aires: Siglo XXI, 2010.

BAKHTIN, M. (Voloshinov). Marxismo e filosofia da linguagem. São Paulo: Hucitec, 1997.

BOLTANSKI, L.; CHIAPELLO, E. O novo espírito do capitalismo. São Paulo: Martins Fontes, 2009.

CASAQUI, V. Apontamentos para o estudo da cultura da inspiração: produção de narrativas e o ideário da sociedade empreendedora. In: $\mathbf{5}^{\circ}$ COMUNICON - Congresso Internacional em Comunicação e Consumo. São Paulo: ESPM, 2015.

8 Fonte: https://economia.uol.com.br/ultimas-noticias/redacao/2012/06/01/conheca-a-historia-de-bel-pesce-amenina-que-conquistou-o-vale-do-silicio.htm. Acesso em: 6/3/2018. 
ChaRAUDEAU, P. Discurso das mídias. São Paulo: Contexto, 2007.

DARDOT, P.; LAVAL, C. A nova razão do mundo: ensaio sobre a sociedade neoliberal. São Paulo: Boitempo, 2016.

DRUCKER, P. F. Inovação e espírito empreendedor: prática e princípios. São Paulo: Cengage Learning, 2011.

EHRENBERG, A. O culto da performance: da aventura empreendedora à depressão nervosa. Aparecida - SP: Idéias \& Letras, 2010.

FOUCAULT, M. Birth of biopolitics. New York: Palgrave Macmillan, 2008.

FREIRE FILHO, J. (org.) Ser feliz hoje: reflexões sobre o imperativo da felicidade. Rio de Janeiro: Ed. FGV, 2010.

GALLO, C. TED: falar, convencer, emocionar: como se apresentar para grandes plateias. São Paulo: Saraiva, 2014.

GALOUJ, F. "Inspiration Economy": A New Journal. Journal of Inspiration Economy: an International Journal, vol.1, issue 1, sept 2014, p.7-13. Disponível em: http://journals.uob.edu.bh/JIE/contents/ volume-39/articles/article-838. Acesso em: 1/5/2017.

GEERTZ, C. A interpretação das culturas. Rio de Janeiro: LTC, 2008.

HAN, B.-C. La sociedad de la transparencia. Herder Editorial: Barcelona, 2013.

MOUFFE, C. Sobre o político. São Paulo: Editora WMF Martins Fontes, 2015.

PESCE, B. A menina do vale: como o empreendedorismo pode mudar sua vida. São Paulo: Enkla, 2015.

PRADO, J. L. A. Acontecimento, tensividade e circuito dos afetos. Anais do XXV Encontro Anual da Compós, Universidade Federal de Goiás, 07 a 10 de junho de 2016. Disponível em: < http://www. compos.org.br/biblioteca/compos_aidar_2016_3321.pdf>. Acesso em: 1/5/2017.

SAFATLE, V. O circuito dos afetos. São Paulo: Cosac Naify, 2015.

SALGADO, J. Entre solitários e solidários: o empreendedor nos discursos da Folha de S. Paulo (19722011). Tese (Doutorado em Comunicação e Cultura) - Universidade Federal do Rio de Janeiro - UFRJ, Escola de Comunicação - ECO, 2016.

SILVA, F. A. A realidade que inspira. In: PESCE, B. A menina do vale: como o empreendedorismo pode mudar sua vida. São Paulo: Enkla, 2015, p.11-14.

TAYLOR, C. A ética da autenticidade. São Paulo: É Realizações Ed., 2011.

THRASH, T. M.; ELLIOT, A. J. Inspiration as a psychological construct. Journal of Personality and Social Psychology, 2003, vol. 84, no. 4, p. 871-889.

VAN DIJK, T. A. La ciencia del texto. Barcelona: Paidós, 1978. 